$\mathbf{s}$

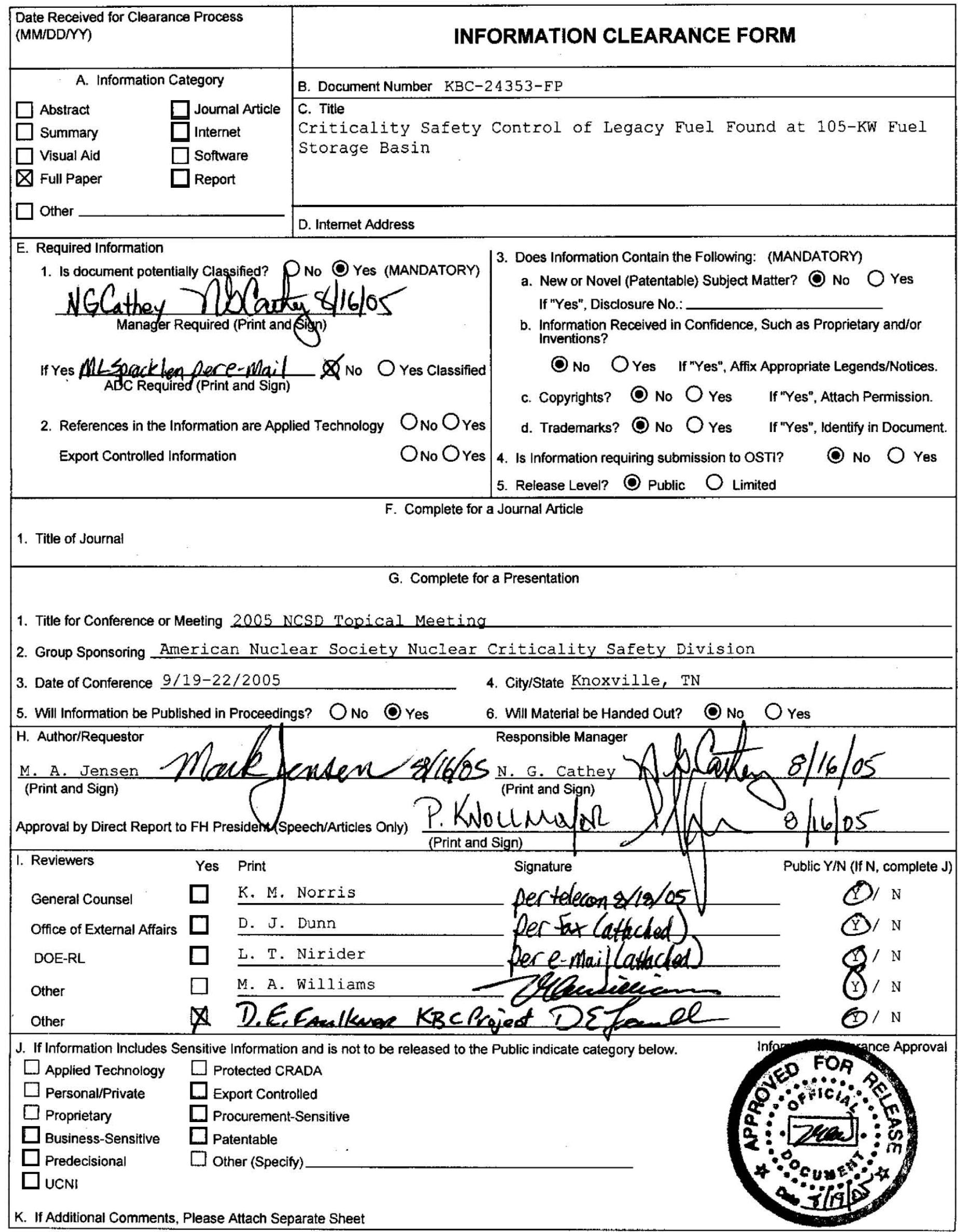


KBC-24353-FP

Revision 0

\section{Criticality Safety Control of Legacy Fuel Found at 105-KW Fuel Storage Basin}

Prepared for the U.S. Department of Energy

Assistant Secretary for Environmental Management

Project Hanford Management Contractor for the

U.S. Department of Energy under Contract DE-AC06-96RL13200

\section{Fluor Hanford}

P.O. Box 1000

Richland, Washington 
KBC-24353-FP

Revision 0

\section{Criticality Safety Control of Legacy Fuel Found at 105-KW Fuel Storage Basin}

Date Published

August 2005

To Be Presented at

2005 NCSD Topical Meeting

American Nuclear Society

Knoxville, TN

Sept. $19-22$

Published in

2005 NCSD Topical Proceedings

Prepared for the U.S. Department of Energy

Assistant Secretary for Environmental Management

Project Hanford Management Contractor for the

U.S. Department of Energy under Contract DE^AC06-96RL13200

\section{Fluor Hanford}

P.O. Box 1000

Richland, Washington

Copyright License

By acceptance of this article, the publisher and/or recipient acknowledges the U.S. Government's right to retain a nonexclusive, royalty-free license in and to any copyright covering this paper.

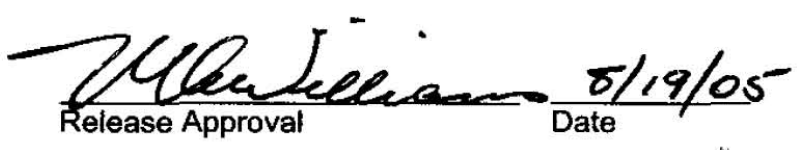


KBC-24353-FP

Revision 0

LEGAL DISCLAIMER

This report was prepared as an account of work sponsored by an agency of the United States Government. Neither the United States Government nor any agency thereof, nor any of their employees, nor any of their contractors, subcontractors or their employees, makes any warranty, express or implied, or assumes any legal liability or responsibility for the accuracy, completeness, or any third party's use or the results of such use of any information, apparatus, product, or process disclosed, or represents that its use would not infringe privately owned rights. Reference herein to any specific commercial product, process, or service by trade name, trademark, manufacturer, or otherwise, does not necessarily constitute or imply its endorsement, recommendation, or favoring by the United States Government or any agency thereof or its contractors or subcontractors. The views and opinions of authors expressed herein do not necessarily state or reflect those of the United States Government or any agency thereof.

This document is available to the U.S. Department of Energy and its contractors, in paper from the Office of Scientific and Technical Information (OSTI). It is available for sale to the public from the national Technical Information Service (NTIS).

This report has been reproduced from the best available copy. Available in paper copy. 


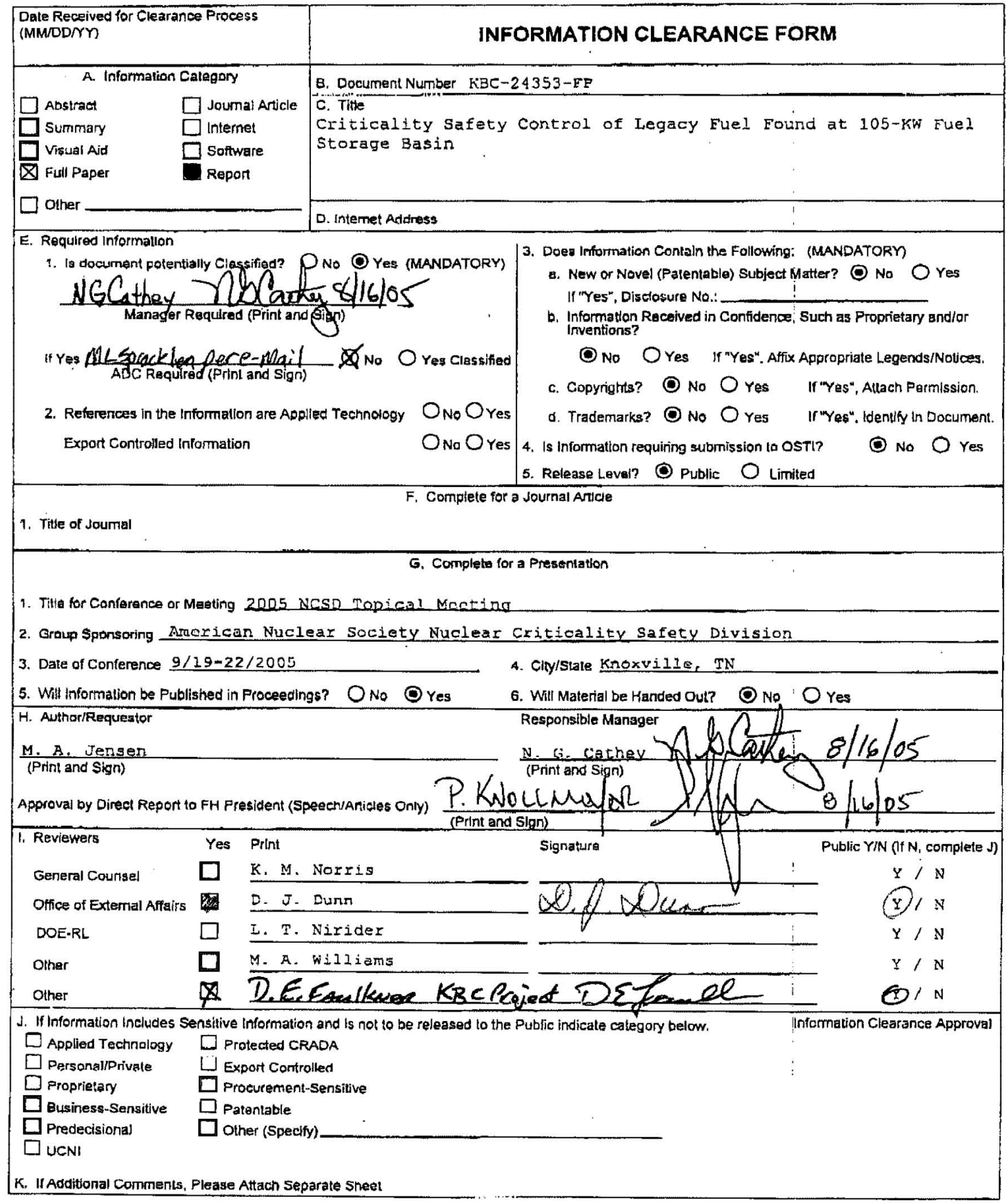


Mark A. Jensen

\title{
CRITICALITY SAFETY CONTROL OF LEGACY FUEL FOUND AT 105-KW FUEL STORAGE BASIN
}

\author{
Mark A. Jensen \\ Fluor Hanford Inc. \\ P.O. Box 1000 \\ Richland, WA 99352 \\ mark_a jensen@rl.gov
}

\begin{abstract}
In August 2004, two sealed canisters containing spent nuclear fuel were opened for processing at the Hanford Site's K West fuel storage basin. The fuel was to be processed through cleaning and sorting stations, repackaged into special baskets, placed into a cask, and removed from the basin for further processing and eventual dry storage. The canisters were expected to contain fuel from the old Hanford $C$ Reactor, a graphite-moderated reactor fueled by very low-enriched uranium metal. The expected fuel type was an aluminum-clad slug about eight inches in length and with a weight of about eight pounds. Instead of the expected fuel, the two canisters contained several pieces of thin tubes, some with wire wraps. The material was placed into unsealed canisters for storage and to await further evaluation.

Videotapes and still photographs of the items were examined in consultation with available retired Hanford employees. It was determined that the items had a fair probability of being cut-up pieces of fuel rods from the retired Hanford Plutonium Recycle Test Reactor (PRTR). Because the items had been safely handled several times, it was apparent that a criticality safety hazard did not exist when handling the material by itself, but it was necessary to determine if a hazard existed when combining the material with other known types of spent nuclear fuel. Because the PRTR operated more than 40 years ago, investigators had to rely on a combination of researching archived documents, and utilizing common-sense estimates coupled with bounding assumptions, to determine that the fuel items could be handled safely with other spent nuclear fuel in the storage basin.
\end{abstract}

As older DOE facilities across the nation are shut down and cleaned out, the potential for more discoveries of this nature is increasing. As in this case, it is likely that only incomplete records will exist and that it will be increasingly difficult to immediately characterize the nature of the suspect fissionable material and its criticality hazards.

\section{INTRODUCTION}

In 2004, during fuel removal activities at the 105-K West (KW) Fuel Storage Basin at the Hanford Site in Washington State, two sealed storage canisters, which were thought to contain fuel from the old Hanford C Reactor, were opened for processing through the basin fuel removal system equipment. Unexpectedly, the canisters contained items that did not resemble any fuel types the KW Basin operators had seen during the processing campaign. The material was returned to storage for further evaluation by the $\mathrm{K}$ Basins Closure Project (KBCP) Process Engineering organization. Later, the canister contents were examined and videotaped, again without determining what the material was. A review of the videotape by Process Engineering, Nuclear Safety, and other personnel determined that the suspect items were probably cut-up 
pieces of fuel pins from a long-retired Hanford experimental reactor, the Plutonium Recycle Test Reactor (PRTR). As PRTR fuel had considerably different characteristics than the old Hanford Single-Pass Reactor (SPR) fuel, it was necessary to carefully consider the criticality safety ramifications of this discovery before further handling.

\section{HISTORY}

The Hanford Site was established in 1943 as part of the World War II Manhattan Project. Hanford was chosen as the site for plutonium production and initially three large production reactors were built, designated $\mathrm{B}, \mathrm{D}$, and $\mathrm{F}$ reactors. The reactors were graphite moderated, water-cooled, and fueled with natural uranium. The fuel elements were uranium slugs in aluminum cans, approximately eight inches in length and one and one-half inches in diameter (Figure A-1). Water coolant was once-through treated Columbia River water; hence the term Single-Pass Reactor. After World War II ended, the production capabilities were gradually expanded until there were eight SPR plutonium production facilities $(B, C, D, D R$ [for Replacement], F, H, K East, and $\mathrm{K}$ West). The reactors underwent many design modifications including power upgrades that required the use of slightly enriched fuel, generally $0.95 \mathrm{wt} \%$ and $1.25 \mathrm{wt} \%{ }^{235} \mathrm{U}$. Higher enrichments were also used for experimental purposes, including small amounts of $95 \mathrm{wt} \%{ }^{235} \mathrm{U}$ in an aluminum matrix at the $\mathrm{C}$ Reactor.

The final design for graphite moderated water-cooled reactors was the $\mathrm{N}$ Reactor, which unlike the older reactors recirculated its cooling water. The fuel design was considerably different as well. $\mathrm{N}$ Reactor fuel, although still very low enriched (mostly $0.95 \mathrm{wt} \%$ with some $1.25 \mathrm{wt} \%$ ), was larger, up to 26 inches in length and with an outside diameter of approximately 2.4 inches. N reactor fuel assemblies weighed between 20 and $50 \mathrm{lbs}$. depending on length. The fuel design was a "tube in tube" design that allowed for better circulation of cooling water around the fuel assemblies. The fuel was also zirconium-clad rather than aluminum-clad (Figure A-2).

The single-pass reactors began shutting down in 1965. K East was the final single-pass reactor to operate, shutting down in 1971. N Reactor continued to operate until 1987. During much of $\mathrm{N}$ Reactor's operating life, Hanford was not processing spent nuclear fuel. After the $\mathrm{N}$ Reactor storage basin began filling up, the storage basins at the $\mathrm{K}$ East and $\mathrm{K}$ West reactors were reactivated and irradiated $N$ Reactor fuel began to fill those basins as well. When $\mathrm{N}$ Reactor was shut down in 1987, its basin was emptied and all of the irradiated (spent) nuclear fuel was consolidated in the two $\mathrm{K}$ Basins. In addition, cleanout of the $\mathrm{K}$ Basins and the older SPR basins throughout the 1970's and into the 1980's turned up quantities of SPR fuel. Some of this fuel was sent to $\mathrm{N}$ Reactor's basin for characterization before final storage at the K Basins.

Although the single-pass reactors were generally fueled with very low enriched uranium, C Reactor was often used to test different materials and fuel types. One such experimental fuel type was known as "J metal" and was a matrix of $93 \mathrm{wt} \%{ }^{235} \mathrm{U}$ and aluminum. Therefore, when SPR fuel was discovered at $\mathrm{C}$ Reactor basin cleanout during decontamination and decommissioning activities, it was handled under very restrictive limits (based on the $\mathrm{J}$ metal critical mass) until the enrichment could be verified by making careful measurements of the fuel length and weight. The earliest known application of the restrictive limits was in 1983. 


\subsection{History of the Legacy Fuel}

In 1984, some material was recovered at the C Reactor Basin and sent to $\mathrm{N}$ Reactor for characterization and storage. The material was stored under the unidentified enrichment limits in 1987 and was shipped to the K West basin in 1989. In 1990, the material was shipped back to the N Reactor basin for examination by Pacific Northwest National Laboratory (PNNL) personnel. The examination was to determine whether or not the material was fuel based on the presence of ${ }^{137} \mathrm{Cs}$ spikes, a common fission product. No request was made to determine fuel type or origin. Based on the presence of cesium, the material was declared fuel and placed into two sealed canisters for shipment to the $\mathrm{K}$ West basin. A total of 43 items were identified as being fuel and they were packaged according to the restrictive "unidentified enrichment" limits for all C Reactor SPR fuel (a maximum 30 pieces of fuel per canister). The fuel was stored in the sealed canisters at KW from 1990 until the present. None of the personnel involved in the examination and packaging at $\mathrm{N}$ Reactor had worked at the $\mathrm{C}$ Reactor or any other SPR facility during their operating days. In the words of a former Basin Operations manager, they were all in grade school when the reactors began shutting down. Therefore, these individuals did not recognize that the material being packaged could not have been SPR fuel. The assumption was made that it was simply unusual material, probably from an experiment. In addition to sometimes using exotic reactor fuels, C Reactor (and in fact all of the SPR reactors) had numerous "test holes" for irradiating material for experimental purposes.

For nearly 15 years, incorrect assumptions were made by the author and others that the canisters contained $\mathrm{J}$ metal. This assumption was made because the canisters were sealed making visual verification impossible, and because the fuel was listed on the material balance as "unidentified enrichment SPR" fuel. None of the personnel working at the K Basins, including the author, had ever actually seen $J$ metal but some vague descriptions were available in archived documents. In fact, it was assumed that when the canisters were opened during final processing prior to removing the fuel from the K West basin, the contents would turn out to be standard 0.95 $w t \%$ or natural uranium SPR fuel elements. The discovery that they were something entirely different caused some consternation (Figure A-3). However, even considering that the fuel was not SPR fuel, the very restrictive limits designed for the highly enriched $\mathrm{J}$ metal ensured that a similar amount of plutonium would also be safe to handle. Throughout the 14 years of storage and the brief period of handling the suspect material, these restrictive limits were complied with at all times, including after Operations personnel determined the material was not SPR fuel.

\section{RESPONSE}

The immediate response by Operations personnel was to return the suspect items to unsealed canisters in accordance with the unidentified enrichment limits. The items were returned to the main basin storage area. The assumption was made that the items might just be debris; however, compliance with the restrictive unidentified enrichment SPR limits continued. A few days later, the items were again brought to the processing area and videotapes were made of the contents. The items were again returned to storage. 


\subsection{Examination by Process Engineering and Nuclear Safety}

After examining the videotapes, the $\mathrm{K}$ Basin Closure Project Process Engineering organization contacted the Nuclear Safety organization for advice on how to identify the items. The Project Criticality Safety Representative (the author) concurred with Process Engineering that although some of the items in the two canisters were SPR fuel, some were only debris and some items could not be identified as either SPR fuel or debris of SPR origin. Interviews with knowledgeable personnel revealed that the items resembled fuel pins from the Idaho Falls Experimental Breeder Reactor (EBR). Some of the suspect pieces also resembled N Reactor "inner" fuel elements.

This theory led to several avenues for finding information. Process Engineering and Nuclear Safety began to gather information on EBR fuel to determine if it was possible that the suspect material came from that source. This effort quickly led to the conclusion that the material did not come from the EBR. Also considered and rejected was the possibility that the fuel was from Hanford's Fast Flux Test Facility. The confirmation or rejection of the presence of $\mathrm{N}$ Reactor inner fuel elements would have to wait until the material could be examined and measured.

The author contacted the engineer who originally requested the criticality safety limits for $\mathrm{J}$ metal back in 1983. This engineer currently works for PNNL. Although he remembered requesting criticality limits for $\mathrm{C}$ Reactor $\mathrm{J}$ metal, he did not have knowledge of the specific items in question. Fuel had been recovered from C Reactor many times between 1983 and 1991. He showed the photographs of the suspect material to some older co-workers, who suggested the possibility they might be pieces of fuel rods from the long-retired Plutonium Recycle Test Reactor. This reactor operated in Hanford's 300 Area in the late 1950's to early 1960's to test the feasibility of recycling plutonium into reactor fuel.

In exploring the possibility that the material was PRTR fuel, Hanford archives were researched for PRTR-related documents. The documents that were found tended to confirm this preliminary identification. Attempts to locate current or retired Hanford workers with specific knowledge of the questionable material and PRTR fuel were met with little success. One notable exception was a former $\mathrm{K}$ Basins engineer who had worked on PRTR fuel design many years before. He confirmed the wire-wrapped segments found at $\mathrm{K}$ West closely resembled the wirewrapped PRTR fuel rods (Figures A-4 and A-5). However, no one could be found to confirm that PRTR fuel was either examined at $C$ Reactor (which had an underwater fuel examination facility) or was irradiated at $\mathrm{C}$ Reactor, possibly in a test hole irradiation facility as part of the fuel design validation process for PRTR. Both of these theories for the origin of the suspect material were advanced but no evidence to confirm either one was found. Research also determined that the $\mathrm{K}$ East reactor was used for small-scale irradiation to support fuel designs, including prototype PRTR fuel rods and bundles.

\section{DETERMINATION OF CRITICALITY SAFETY LIMITS}

The reactivity of SPR fuel elements is well understood. Storage and handling limits for irradiated SPR fuel have been used successfully and essentially unchanged for 50 or more years. 
This extensive knowledge was used to establish the restrictive piece count limit on any recovered $\mathrm{C}$ Reactor fuel until enrichment could be verified. The suspect PRTR fuel, however, posed a problem. Clearly, storing the small amount of suspect fuel under the $\mathrm{J}$ metal limits was safe, as the material had been stored and handled under those limits several times in the past several years. However, how safe was it? Could the material be safely mixed with other fuel types and removed from the $\mathrm{K}$ West basin? What are the safe limits?

A search of available records was conducted to find useful records. Hanford has an electronic archive system known as the Records Management Information System (RMIS) in which virtually every unclassified document generated at Hanford since 1943 has been scanned and stored in a searchable database. A search using the key word "PRTR" turned up enough documents to begin understanding the PRTR fuel design and its reactivity characteristics.

\subsection{PRTR Fuel Design}

Research on RMIS determined that there were two types of PRTR fuel assemblies, either a seven-rod cluster or a 19-rod cluster. The seven-rod cluster had six fuel rods in a ring around a central rod. The 19-rod cluster consisted of a seven-rod cluster surrounded by an additional 12

rods. Some of the rods had a wire wrap to maintain proper fuel rod spacing within the assembly, and possibly also to allow for coolant flow around the component rods. This is theorized to be the wire wrap visible in some of the KW Basin suspect fuel pieces.

The fissionable material content of the fuel rod was either a plutonium-aluminum alloy or a mixture of $\mathrm{UO}_{2}$ and $\mathrm{PUO}_{2}$. The plutonium-aluminum alloy was 1.8 percent plutonium by weight. For the mixed oxide fuel, the uranium was either natural or depleted uranium (less than or equal to $0.72 \mathrm{wt} \%{ }^{235} \mathrm{U}$ ). Several different oxide mixtures were used, ranging from $0.5 \mathrm{wt} \%$ $\mathrm{PuO}_{2}$ up to a maximum of $4.0 \mathrm{wt} \% \mathrm{PuO}_{2}$ (BNWL-CC-209, ARH-959 1). The seven-rod cluster consisted of $1.8 \mathrm{wt} \%$ plutonium in the plutonium-aluminum alloy, was $7 \mathrm{ft} 4 \mathrm{in}$. in length, and contained $270 \mathrm{~g}$ of plutonium (HW-59786). Each rod of the 19-rod clusters was approximately $0.56 \mathrm{in}$. in diameter and had a fuel region approximately $90 \mathrm{in.} \mathrm{long} \mathrm{(HW-65277).} \mathrm{A} \mathrm{"graded}$ core" (assumed to be a single fuel rod) consisted of two depleted $\mathrm{UO}_{2}$ pellets at 12.5 grams per pellet at each end of the fuel column. The rest of the column contained 36.5 grams of mixed oxide at $1 \mathrm{wt} \% \mathrm{PuO}_{2}, 1743$ grams of either $2 \mathrm{wt} \%$ or $4 \mathrm{wt} \% \mathrm{PuO}_{2}$ mixed oxide, and 12.5 grams of $1 \mathrm{wt} \% \mathrm{PuO}_{2}$ mixed oxide (BNWL-CC-209). Conservatively assuming that all of the mixed oxide was $4 \mathrm{wt} \% \mathrm{PuO}_{2}$, each rod contained a maximum of 70 grams of $\mathrm{Pu}$ and a complete 19-rod cluster contained about 1334 grams of $\mathrm{Pu}$.

\subsection{Criticality Safety Limits for the Suspect Fuel}

For purposes of the immediate criticality safety evaluation of the suspect fuel in the KW basin, it was assumed that all the suspect pieces contained $4 \mathrm{wt} \% \mathrm{PuO}_{2}$ in order to determine a bounding mass.

Presented with this unusual condition of a fuel storage basin found to contain potential fuel that had not been analyzed and had not been authorized by the Department of Energy, Fluor Hanford declared the situation an Unreviewed Safety Question and requested permission to 
perform limited non-destructive examination of the suspect items. DOE concurred, provided a criticality safety evaluation report was prepared to show that the small amount of suspect fuel could be handled safely. DOE recognized that although the suspect items could not be positively identified as to origin and fissionable material content, bounding estimates could be prepared to show that the material could be handled safely. The criticality safety evaluation report was prepared, and imposed the following administrative controls on the operation (HNF-23280):

- The canisters will be emptied one at a time on the processing table for examination.

- All material in the first canister will be sorted and moved out of the way before the second canister is opened.

- Items that cannot be identified as N Reactor or SPR fuel, or non-fuel debris, will be set aside. The suspect items will be placed into a canister or canisters and returned to the main basin for storage pending final disposition. The suspect items may be examined as necessary to determine final disposition.

- All suspect materials may be placed into a single canister. This canister (or canisters if multiple canisters are used) does not require any special handling or storage once filled.

- All other items sorted from the suspect material (N Reactor or SPR fuel [pieces or scrap], or non-fuel debris) will be handled in accordance with existing limits.

\section{FUEL EXAMINATION}

On December 1, 2004, the canisters containing the suspect fuel were brought to the $\mathrm{K}$ West Basin fuel retrieval system primary processing table for examination. This operation took place under approximately 15 feet of water. A special tray was fabricated with scales to measure diameter and length. Probes were fabricated to insert into the tubes to determine if they were empty (hollow) or contained material. Finally, each piece was measured for gross radioactivity with an $\mathrm{RO}-7$ type radiation probe. It was hoped that the suspect pieces would show no significant radioactivity and could therefore be disposed of as debris.

Out of the original 43 pieces contained in the two canisters, 15 were identified as being the suspect PRTR fuel rod pieces. The remaining items were successfully identified as being SPR fuel, non-fuel debris of SPR origin, or other non-fuel debris. The 15 pieces showed no consistency in length - there were eight different lengths for the 15 items. The lengths do not match any PRTR fuel rod length; however it is apparent that the pieces were deliberately cut into shorter lengths (perhaps simply to be able to fit them into standard fuel canisters, although some pieces had beveled cuts that could have been made for examination purposes). The measured diameters (between 0.500 and 0.600 inches) correspond fairly well with the reported diameters of PRTR rods. When the items were probed, it was discovered that all of them had some material inside, which appeared to be a solid piece rather than pellets. This is consistent with actual PRTR rods, which had solid ceramic fuel inserts for most of the fuel region, with pellets at the enids. Based on the probe test, the suspect items could not be ruled out as being fuel. It was quickly established that none of the pieces were $\mathrm{N}$ Reactor fuel inner elements, based on both diameter measurements and visual observation by experienced personnel.

The examination measured the lengths of the 15 pieces, which ranged from three inches to 22 inches. The combined length of all the pieces is about 182 inches. Assuming that the 
pieces are from a 19-rod cluster single rod (fuel region of 90 inches), the suspect pieces represent slightly more than two rods. Since each rod contained 70 grams of plutonium, the total amount present in the 15 pieces of suspect fuel is about 140 grams. This amount is safely subcritical under any circumstances.

The radiation probe results proved to be somewhat of an enigma. Past experience with probes of N Reactor and SPR fuel show very high radiation levels, on the order of 50-200 R/hr. at contact. Typical basin debris shows dose rates well below $1 \mathrm{R} / \mathrm{hr}$. The fifteen suspect items had dose rate readings of between $1-11 \mathrm{R} / \mathrm{hr}$. The items were considerably more radioactive than one would expect for contaminated or even activated debris, but also considerably less radioactive than one would expect for irradiated fuel. Based on the radiation readings and the fact that the pieces were not empty, it could not be stated with certainty that the items did not contain fissionable material. Notwithstanding the original PNNL survey indicating the presence of fission product cesium, the items could have been unirradiated when sent to the C Reactor basin for examination or could have been only lightly irradiated in the reactor. Also, since the material has potentially been in storage for nearly 50 years, it is possible that a large portion of the radioactive fission products have decayed to less radioactive progeny.

\section{FUTURE DISPOSITION}

It is currently assumed that the material is fuel and will have to be disposed of accordingly. The $\mathrm{K}$ Basins Closure Project has removed most of the spent nuclear fuel from both the K West and $\mathrm{K}$ East basins in overpack containers, which are now in dry storage at another Hanford facility. Small amounts of scrap and intact fuel remain in both basins, which will, in the future, be packaged into an overpack. The suspect PRTR fuel will probably be packaged with the N Reactor and SPR fuel. A criticality safety analysis will be performed to verify the safety of the proposed operation. Although criticality safety has been demonstrated for storage and examination of the suspect fuel in the $\mathrm{K}$ West basin, it is yet to be determined that the material can be safely mixed with the other fissionable material remaining in the basin. The safety of drying the material and long-term storage must also be addressed. Finally, a safety basis amendment will need to be prepared and presented to DOE for approval, as the safety basis documents for the $\mathrm{K}$ Basins and for the storage facility do not currently discuss this type of material.

\section{LESSONS LEARNED}

As older facilities in the DOE weapons complex are shut down and deactivated, it is likely that fissionable material will be found in either unexpected forms or places. The found material will probably be well-characterized and can be safely handled under existing criticality safety limits, as is the case with genuine SPR fuel that is still occasionally found during work activities at the $\mathrm{K}$ Reactor basins and some of the other SPR basins. However, unusual and possibly unknown items may be found. The following lessons can be learned from the $\mathrm{K}$ West basin incident:

- Research archived documents to obtain as much information as possible. Standards from 30,40 , or 50 years ago are not the same as today and it is possible that descriptions will 
be frustratingly vague. It is important to review as many documents as possible to put the pieces together to understand what must be dealt with.

- Be conservative. Recognize that the knowledge is limited and it may be impossible to state the reactivity of the material. It should be possible to develop bounding safe masses or arrangements to safely disposition the material, based on sound engineering estimates by members of the criticality safety organization.

- Recognize that in currently active (non-decontamination and decommissioning) facilities, today's material can be tomorrow's legacy material. Document as fully as possible. Unusual items that do not contain fissionable material should be segregated and disposed to reduce the potential that future workers will be confused or unnecessarily restrict themselves due to concerns about criticality safety. Unusual items that $d o$ contain fissionable material should be fully documented on isotopic content and history.

- Interview operators and/or retired workers to get an insider's view of a plant's operating history. It is easy to neglect collecting this knowledge from workers because of the pressures of work, but it can be nearly impossible to reconstruct operating history when personnel who can answer the questions have retired, moved away, or died.

- If necessary, consult nationally recognized criticality safety experts for advice. In this case, it was unnecessary because the solution was relatively easy to come by, but other cases may be more difficult to resolve.

- Radiation measurements, combining gross dose rates and gamma spectra analyses to determine the presence of fission products, may help determine if the questionable material is actually fuel.

\section{CONCLUSIONS}

Legacy fissionable materials are a fact of life at aging DOE facilities. Often these materials come with very little history, as in the case of the $\mathrm{K}$ West basin suspect PRTR fuel. Attempts must be made to locate archived documents, conduct measurements where possible, make conservative estimates and describe the material and its reactivity to the fullest extent possible. As legacy material is found, it is prudent to remember that today's familiar materials may become tomorrow's legacy items. It is important to provide future generations as much information as possible to assist them in dispositioning these materials.

\section{Acknowledgements}

Eugene L. Benjamin, Pacific Northwest National Laboratories

Robert M. Boger, COGEMA Engineering

David G. Erickson, Fluor Government Group

David Faulkner, DOE-RL

Robert H. Meichle, Retired

Francis W. Moore, Fluor Hanford

Tom Nirider, DOE-RL

Donald R. Precechtel, Retired

Hans Toffer, Fluor Government Group 


\section{References}

ARH-600, 1968, Criticality Handbook, 1980 Revision, Atlantic Richfield Hanford Company, Richland, Washington.

ARH-959 1, 1968, Criticality Analysis of PRTR Fuel Processing in the PUREX Plant - Part 1: Receipt and Storage of Fuels Containing up to $2.0 \mathrm{wt} \% \mathrm{PuO}_{2}$ in $\mathrm{UO}_{2}$, Atlantic Richfield Hanford Company, Richland, Washington.

BNWL-CC-209, 1965, Status Report \#2-PRTR High Density Core, Battelle Northwest, Richland, Washington.

HNF-23280 Rev 0, 2004, CSER 04-037: Criticality Safety of Handling and Storage of Suspect, Potentially Fuel-Bearing Debris Found at the 105-KW Basin, Fluor Hanford, Inc., Richland, Washington.

HW-59786, 1959, "PRTR Fuel Element Nuclear Safety, General Electric, Hanford Atomic Products Operation, Richland, Washington. 


\section{APPENDIX A}

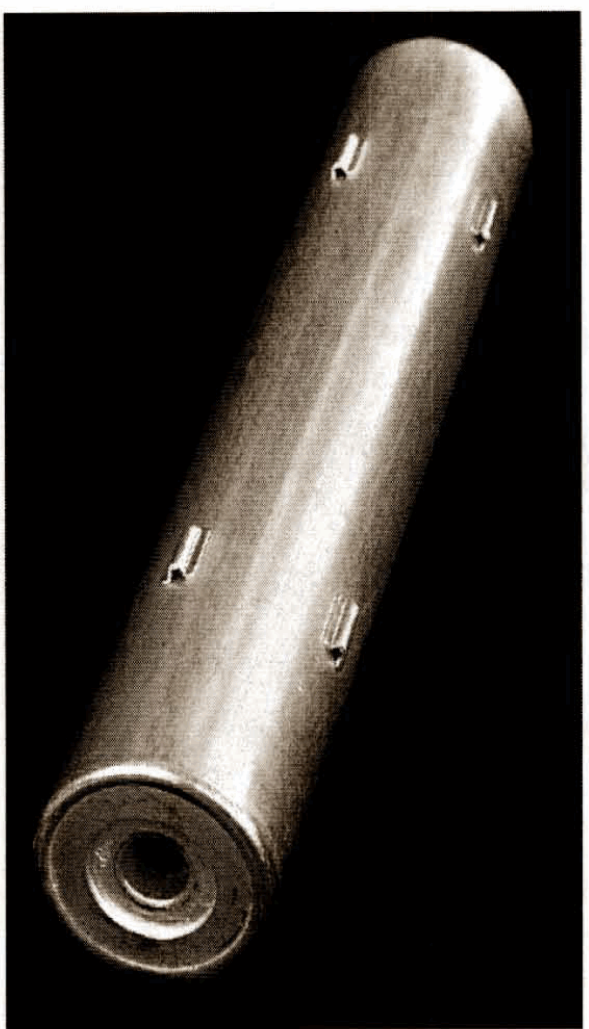

Figure A-1

Typical SPR Fuel Element

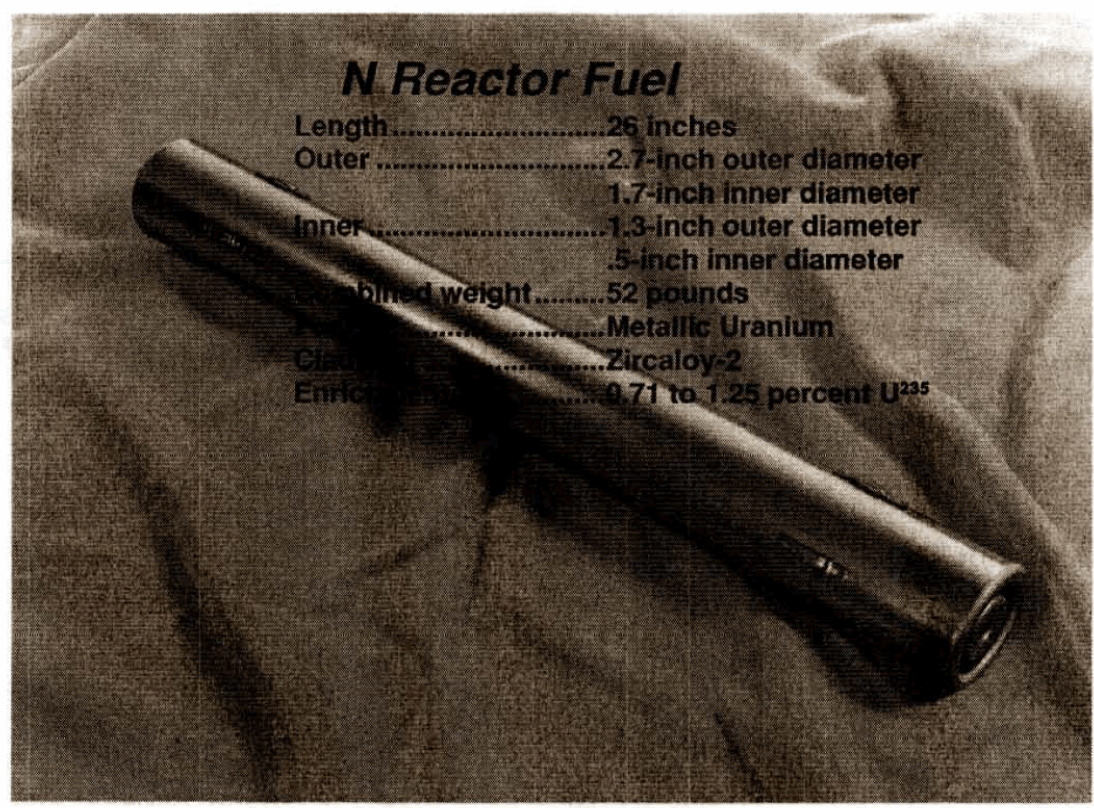

Figure A-2

Typical N Reactor Tube-in-Tube Fuel Assembly 


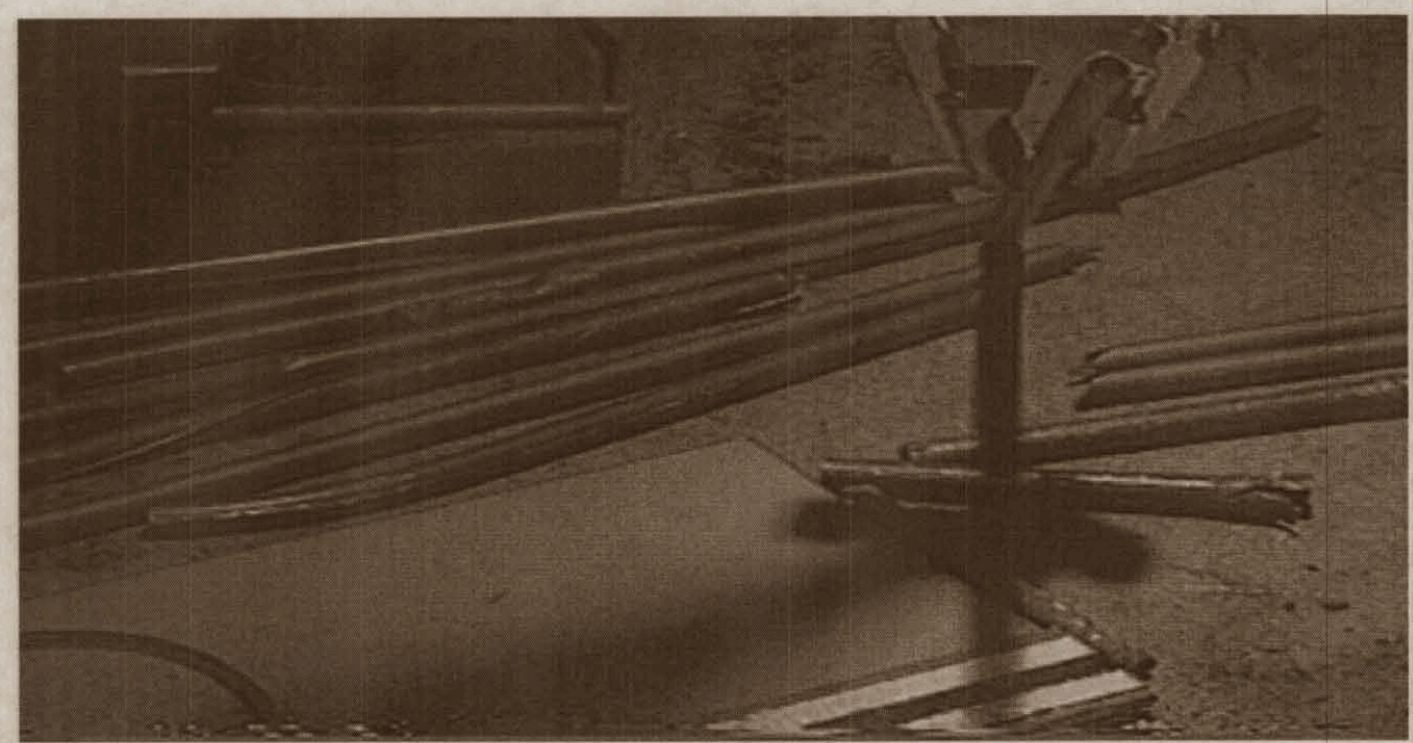

Figure A-3

Collection of Suspect PRTR fuel showing cut pieces, damaged ends, and wire wrap

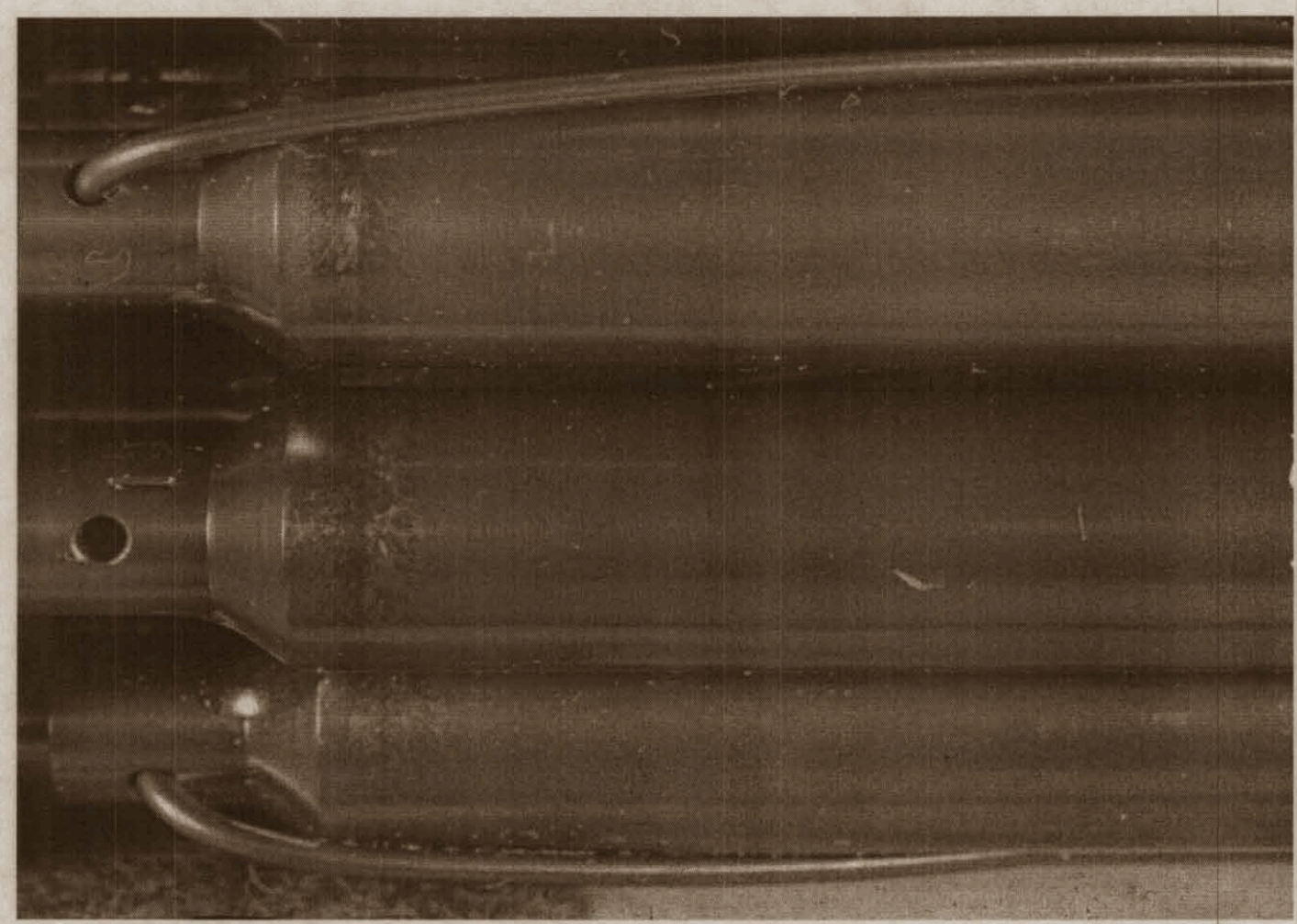

Figure A-4

Close-up of PRTR fuel showing wire wrap 


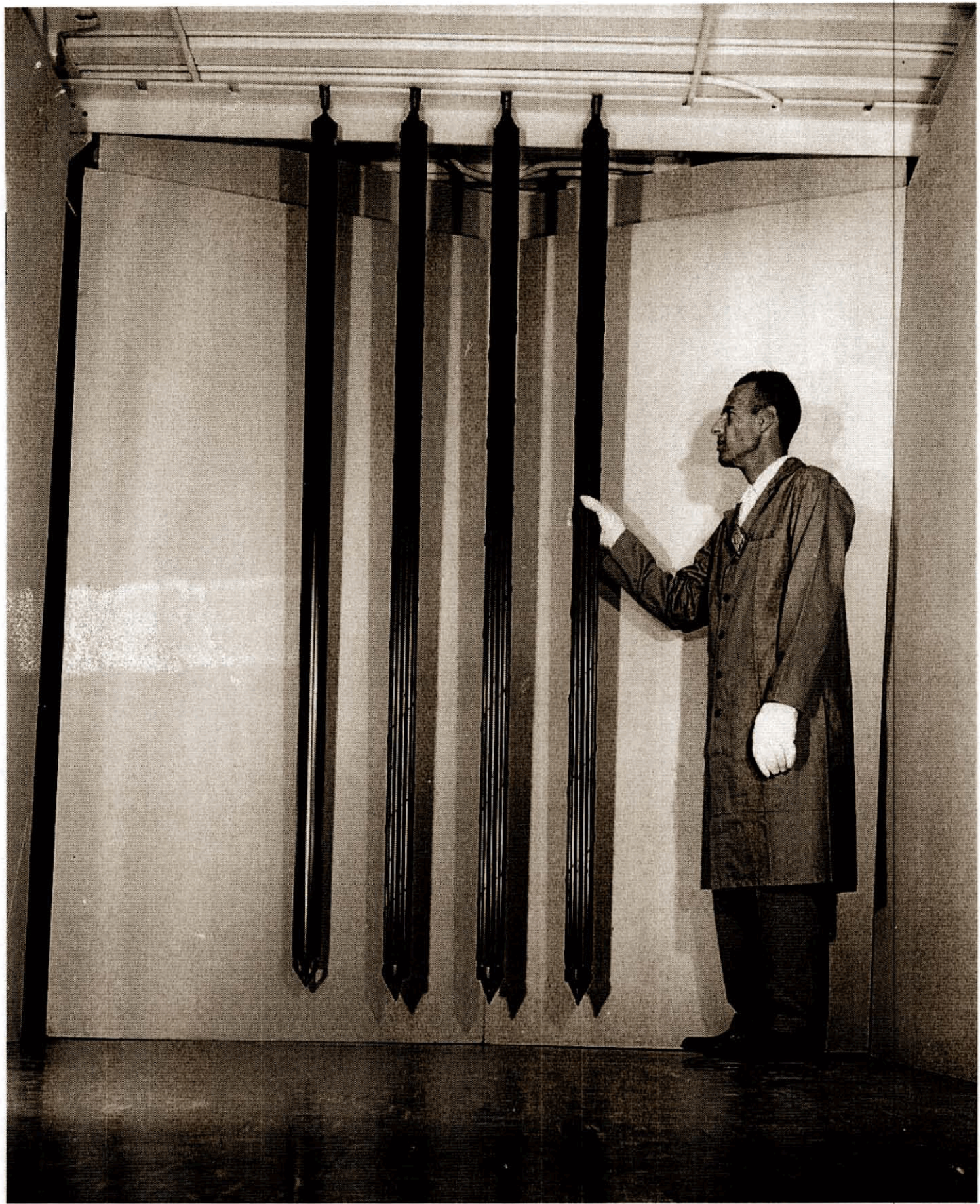

Figure A-5

Photograph of PRTR fuel assemblies showing size perspective 